\title{
FREEDERICKSZ MEDALS FOR 2018 AWARDED TO RUSSIAN CHEMIST AND FOREIGN PHYSICIST
}

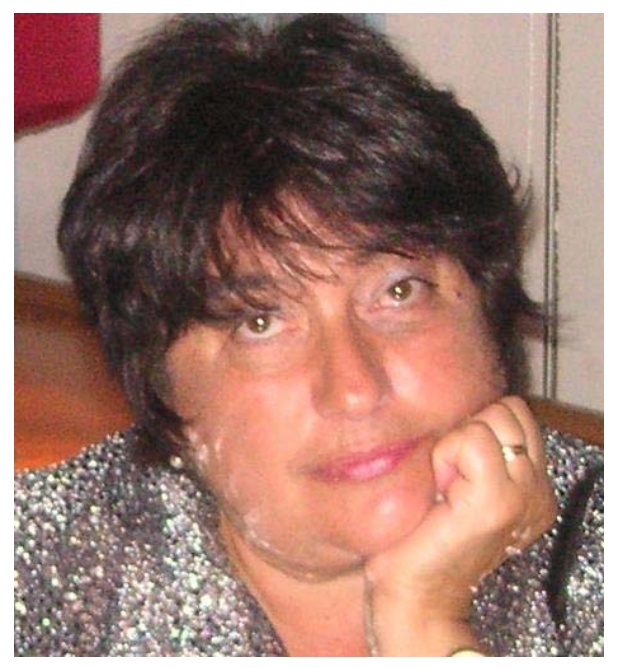

\section{Doctor Sofia Torgova}

Sofia Torgova graduated from Moscow State University with the qualification of "Chemist" in specialty "Organic Chemistry" in 1972, and in 1987 defended her PhD thesis with the title "Synthesis and mesomorphism of compounds containing sixmember saturated carbo- or heterocyclic fragment".

From 1972 until 2004, she worked in Organic Intermediates and Dyes Institute (NIOPIK), as Junior researcher, Researcher, Senior researcher and from 1996 till 2004 as the Head of the Liquid Crystal Chemical Laboratory.

Since 2004 until present time, Torgova works as Senior researcher at the Laboratory of Optoelectronic Processors in Quantum Radiophysics division, of P.N. Lebedev Physical Institute (FIAN), Russian Academy of Sciences.
Sofia Torgova is a specialist in the field of synthesis and characterization of liquid crystals and of organic light emitting materials, polarizing microscopy, dielectric and DSC investigations, thermal properties of liquid crystals, orientation of liquid crystals, textures investigations, thermodynamics of mixtures, hydrogen bonding, dichroic dyes, cis-trans isomerization, polymer dispersed liquid crystals, electro-optical investigation of ferroelectric liquid crystals, etc.

Torgova is an author of more than 100 publications in the Russian and international journals, and more than 75 presentations in the international conferences and schools ( 8 of them were invited talks), 4 copyright certificates and 2 European patents.

One of the papers (Ferroelectric Response and Induced Biaxiality in the Nematic Phase of a Bent-Core Mesogen), which was published in Adv. Funct. Mat., was nominated by European Synchrotron Radiation Facility, Grenoble (France) inside the 5 highlights of 2009.

Sofia Torgova was one of the founder of the Russian Liquid Crystal Society "Sodruzhestvo" and starting from 1992 until present time is the scientific secretary of this Society. She was representative of Russia in the Board of International Liquid Crystal Society in the period 20002004, from 2006 - until present time she is the secretary of Society for information displays, Russian Chapter.

$\mathrm{S}$. Torgova participated in many national and international scientific projects:
1998-2002 - Responsible of the Russian part of the European project "Copernicus" (Programme "PhotoCom") on the topic "Polymer-dispersed liquid crystal materials".

1998-2010 - Board member of the International Russian-Italian Laboratory for the study of orientationally ordered media (OOM-LAB), established in September 1997 among Centro Recherche FIAT, Politecnico di Torino, Institute of General Physics IOFRAN, Moscow, and NIOPIK, Moscow. She participated in the organization of this laboratory and worked in Centro Recherche FIAT as visiting scientist.

From 1998 to 2004, S. Torgova was the responsible of two annual research projects supported by the Russian Ministry of Science. Since 2004 until present time, she participated in more than 20 projects of Russian Foundation of Basic Research (RFBR).

From 1998 to 2000 Torgova was associated to the Italian Project MURST Co-Funds '99.

Torgova S. was scientific responsible of a subcontract with the Politecnico di Torino and the LC Society "Sodruzhestvo" each in the frame of the Agreement between Politecnico di Torino and the Russian Academy of Sciences.

She was one of the organisers of an "Agreement for scientific and educational cooperation" among National Research Nuclear University "MEPHI", P.N. Lebedev Physical Institute (FIAN) of the Russian Academy of Sciences and Polytechnic of Turin (2014-2019), renewed on 2019 till 2024. 
Torgova S. had international scientific collaborations with foreign Universities or Research Centres. She was visiting scientist in Chalmers University of Technology (Goeteborg, Sweden - Prof. S. Lagerwall and Prof. L. Komitov); Raman Research Institute (Bangalore, India - Prof. N.V. Madhusudana); University of Ljubljana (Ljubljana, Slovenia - Prof. S. Zumer); University of S. Paulo (S. Paulo, Brasil Prof. A.M. Figueiredo Neto); European Synchrotron Radiation Facility (Grenoble, France - Prof. C. Ferrero); Università Politecnica delle Marche (Ancona, Italy - Prof. O. Francescangeli); Institute of Solid State Physics of Bulgarian Academy of Sciences (Sofia, Bulgaria - Prof. A. Petrov and Prof. M. Petrov); Universitatea Politehnica din București (Bucharest, Romania - Prof. A.L. Alexe-Ionesku); Ben-Gurion University (Beer Sheva, Israel - Prof. I. Abdulhalim); Politecnico di Torino (Turin, Italy - Prof. A. Strigazzi and Prof. G. Barbero).

Sofia Torgova participated in many national and international Schools and Conferences and was member of the organizing or scientific committees of some of them:

1. International Conference "White Nights Liquid Crystals Conference", Leningrad, USSR, 27 May2 June1991 (Member of Organizing Committee).

2. Liquid Crystal International Conference, Novi Svet, Crimea, Ukraine, 5-12 September 1992 (Member of Scientific Committee).

3. International Conference "Display-94", Otradnoe, Moscow, 22-26 February 1994 (Member of Scientific Committee).

4. $6^{\text {th }}$ Scientific Session of LCS "Sodruzhestvo", Moscow, Graphic Art Inst., 21-30 September 1994 (Member of Organizing Committee).
5. International Conference "Second White nights" on Liquid Crystals, S. Petersburg, May 1995 (Member of Scientific Committee).

6. $9^{\text {th }}$ Scientific Session of LCS "Sodruzhestvo", Samara, Russia, 20-23 May 1996, (Member of Scientific Committee).

7. $10^{\text {th }}$ Scientific Session of LCS "Sodruzhestvo", Moscow, Russia, 20-25 October 1996 (Member of Organizing Committee).

8. International Workshop on "Liquid Crystals and Applications", Ufa, Bashkiria, 2-8 July 1998 (Member of Scientific Committee).

9. $12^{\text {th }}$ Scientific Session of LCS Sodruzhestvo, Moscow, 16 October 1998 (Member of Scientific and Organizing Committee).

10. $8^{\text {th }}$ European Conference on Liquid Crystals, Sesto (BZ), Italy 27 February - 4 March 2005 (Member of International Scientific committee).

11. $14^{\text {th }}$ European Conference on Liquid Crystals, Moscow, Russia, 25-30 June, 2017 (Scientific secretary of the conference).

12. $28^{\text {th }}$ International Liquid Crystals Conference, Lisbon, Portugal, 26-31 July, 2020 (Member of International Advisory Board).

Sofia Torgova is member of editorial board of Journal "Liquid Crystals and their Practical Applications". In 2011 she was awarded by the Basov Prize for the work "Discovery and investigation of the quadratic electro-optical effect in ferroelectric liquid crystals". In 2013 Torgova had Winner Diploma of FIAN scientific works competition for the research "Spiral nanostructures of liquid crystal ferroelectrics". 


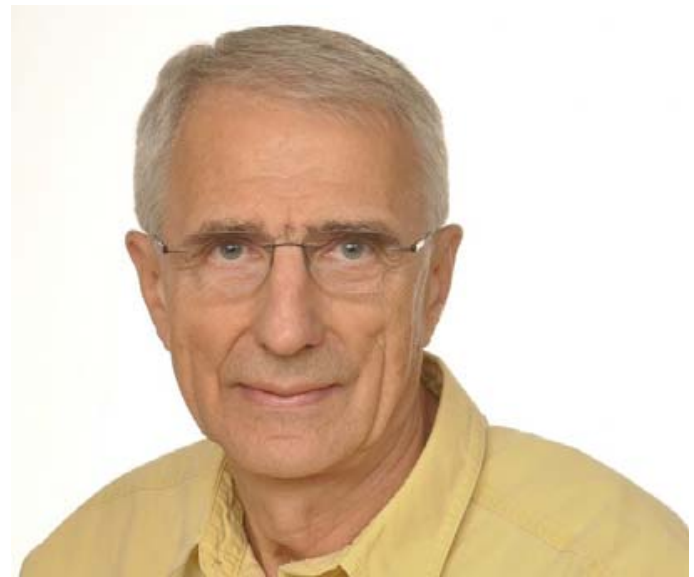

\section{Professor Slobodan Žumer}

Slobodan Žumer graduated from the Physics Faculty University of Ljubljana in 1967 as BSc and in 1972 as MSc, in 1973 he defended his Ph.D. thesis. In the years 1968-1973 he was research and teaching assistant in Physics Department, University of Ljubljana, then during years 1974-1980 Žumer was assistant Professor in the same University. In the period of 1975-1976, Slobodan was postdoctoral Fellow, Physics Department, Université Libre de Bru-xelles, Belgium, then 1981-1987 associate Professor of Physics, Physics Department, University of Ljubljana. In the years 1984-1986 he was visiting Scientist in Liquid Crystal Institute, Kent State University and then in the period 1992-1993 visiting Professor in the same University.
From 1987 to the present time Slobodan Žumer is Professor of Physics, University of Ljubljana \& Scientific Adviser, Jozef Stefan Institute

Professor Žumer is one of the leading experts in the world in the theory, modeling, and simulations of soft matter. The main subjects of his work are: topological soft matter, liquid crystals, colloidal dispersions, colloidal crystals, soft composites, photonic crystals, liquid crystalline elastomers, polymer dispersed liquid crystals. He investigated such phenomena as: ordering, transitions, defects, complex structures, confinement, wetting and dewetting, topology and geometry of soft structures, structural forces, fluctuation forces, Casimir effect, dynamics, hydrodynamics, magnetic relaxation, optics, photonics, plasmonics etc.

Professor Žumer is an author of over 270 papers in international journals and more than 80 publications in international conference proceedings. He is co-editor of 5 books (Taylor and Francis 1996, Kluwer 2001 and 2005, Springer 2006, CRC 2011) and is co-author of 3 US and $1 \mathrm{EU}$ patents.

Žumer is an active member of International $\mathrm{Li}$ quid Crystal Community, in the years 2008-2012 he was President of the International Liquid Crystal Society, in 2004-2008, 2012-2016 - member of the International Liquid Crystal Society Board.

He also participated in the organization of a lot of international conferences:

1. Vice-chair, International conference: Liquids2017, Ljubljana 2017.

2. Co-chair, $6^{\text {th }}$ Workshop on Liquid Crystals for Photonics, Ljubljana 2016.

3. Co-chair of the Planer-Smoluchowski Soft Matter Workshop on Liquid Crystal Colloids, Lviv, Ukraine 2011.
4. Co-director of the $15^{\text {th }}$ Workshop: Liquid Crystal Phases and Nano-structures, Erice, IT 2008.

5. Chairman of the Organizing Committee of the $4^{\text {th }}$ International Workshop on Liquid Crystalline Elastomers, Ljubljana 2007.

6. Member of the Organizing Committee of the European Polymer Congress, Portorož 2007.

7. Co-director of the $13^{\text {th }}$ Workshop Colloids, Interfaces and Liquid Crystals, Erice 2006.

8. Vice-chairman of the Organizing committee of the Inter. Liquid Crystal Conf., Ljubljana, 2004.

9. Co-director of the ESF Exploratory Workshop Liquid Crystal Colloid Dispersions, Bled 2003.

10. Co-director of the NATO Advanced Research Workshop Computational methods for Polymers and Liquid Crystalline Polymers, Erice, 2003.

11. Co-director of the Symposium Basic and Applied Liquid Crystals Research in the Nineties: a Decade of Progress: at International Conf. on Advanced Materials ICAM 2001, Cancun, 2001.

12. Co-director of the NATO Advanced Research Workshop Computer Simulations of Defects in Liquid Crystals including their Relation to Theory and Experiment, Erice, 2000.

13. Co-director of the SILC EU minischool Theory and Modeling of Liquid Crystals, Portoroz, 2000, International conference committees:

- Member of the Scientific Committee of the International Liquid Crystal Conference, Kyoto 2018, Kent 2016, Dublin 2014, Mainz 2012, Krakow 2010, Jeju 2008, Keystone 2006, Edin-burgh 2002, Sendai 2000, Strasbourg 1998, Kent 1996, Budapest 1994. 
- Member of the Scientific Committee of the Topical Meeting on the Optics of Liquid Crystals, Honolulu 2013, Erice 2009.

- Member of the Scientific Committee of the International Liquid Crystal Elastomer Conference, Erice 2015, Shanghai 2013, Lisbon 2011, Kent 2009.

- Member of the Scientific Committee of the International conference Optics 2017.

Professor Slobodan Žumer was supervisor of $20 \mathrm{PhD}$ students.

Professor Žumer has a lot of awards and fellowship: 2017 - National Zois Award for lifetime research achievements. In particular, for his achievements in theoretical physics of anisotropic soft mater.

2016 - Elected as Member of European Academy of Sciences and Arts (EASA) Salzburg.

2014 - Elected as Honored Member of the International Liquid Crystal Society "For his over four decades of pioneering and prolific contributions to the scientific community of soft condensed matter as one of the founding fathers of the physics of liquid crystals...." (http://www.lcinet.kent.edu/ILCS/main/page101/page 117/page219/page219.html) 1990 - Boris Kidric (National) Prize for the research of Polymer Dispersed Liquid Crystals.

1980 - Boris Kidric Foundation Prize for the research of Magnetic Relaxation in Condensed Matter.

2010-2015 - Member of the national scientific board of Natural \& Mathematical Sciences.

2007-2010 - Member of the scientific board of National Research \& Development Agency.

2005-2007 - Dean of the Faculty of Mathematics and Physics, University of Ljubljana.

2003-2005 - National Coordinator for the Research in Physics.

1997-1999 - Head of the Physics Department, Faculty of Mathematics and Physics, University of Ljubljana.

Scientific secretary of LC Society «Sodruzhestvo» Sofia Torgova 